\title{
Mujeres y hombres \\ en la ficción televisiva norteamericana hoy ${ }^{\star}$
}

\author{
María Isabel Menéndez Menéndez" \\ Francisco A. Zurian Hernández *.
}

Recibido: mayo 20 de 2014 - Aceptado: septiembre 13 de

2014

\section{Resumen}

La ficción seriada televisiva contemporánea suele describirse desde conceptos como el riesgo narrativo, la creatividad, la originalidad y también la trasgresión de tópicos técnicos y argumentales. No obstante, algunos análisis realizados desde enfoques epistemológicos no hegemónicos, como los Gender Studies, los estudios feministas, los estudios sobre hombres y masculinidades, los estudios LGBTI o la teoría Queer, entre otros, encuentran que esas trasgresiones no siempre se producen en lo relativo a las identidades genéricas. Mediante una metodología teórica y estética, el presente texto ofrece un recorrido por series paradigmáticas con el objetivo de reflexionar sobre la presencia o ausencia del binarismo de género.

Palabras clave: género, ficción seriada, televisión, cultura popular, estética.

* El presente trabajo se ha desarrollado en el marco del proyecto "Violencia de género y cultura popular: representación y recepción", cofinanciado por el Ministerio de Sanidad, Servicios Sociales e Igualdad del Gobierno de España y el Fondo Social Europeo (referencia 115/12).

** Miembro del Departamento y docente de Comunicación Audiovisual y Publicidad de la Universidad de Burgos, España. Correo: mimenendez@ubu.es

*** Profesor de Comunicación Audiovisual y Publicidad de la Universidad Complutense de Madrid, en el Departamento de Comunicación Audiovisual y Publicidad 1 de la Facultad de Ciencias de la Información. Correo: azurian@ucm.es 


\title{
Women and Men in the US Television Drama Today
}

\begin{abstract}
Contemporary television fiction series is frequently described from concepts such as narrative risk, creativity, originality, and also transgression of technical and argumentative topics. However, some analyses conducted from epistemological non-hegemonic approaches, such as Gender Studies, feminist studies, studies on men and masculinity, LGBTI studies or Queer Theory, among others, have found that such transgressions are not always produced in relation to gender identities. Through a theoretical and aesthetic methodology, this article offers a tour through paradigmatic series with the purpose of making a reflection on the presence or absence of gender binary system.
\end{abstract}

Key words: Gender; series fiction; television; popular culture; aesthetics. 


\section{Introducción}

La ficción seriada televisiva, desde mediados de los años noventa, está siendo considerada desde la crítica audiovisual, el mundo académico y también las audiencias, como el paradigma de televisión de calidad, rompiendo así con un binomio que hasta hace poco se consideraba antagónico y que diferenciaba entre cultura popular y "alta cultura". Esta ficción, vinculada esencialmente a la producción de los canales de pago norteamericanos, suele definirse desde parámetros como el riesgo narrativo, la creatividad, la originalidad e, incluso, la transgresión de tópicos tanto técnicos como argumentales. Sin embargo, algunos análisis que se han preocupado por incorporar enfoques epistemológicos no hegemónicos, como los efectuados desde los Gender Studies, los estudios sobre masculinidades y LGTBI o la teoría Queer, entre otras, encuentran que esa transgresión no siempre se produce en lo relativo a identidades genéricas, pues la mayoría de ficciones consolidan lo que se ha dado en llamar heterosexualidad obligatoria, además de feminidad/ masculinidad normativas ${ }^{1}$. Con todo, existen productos que han sido capaces de romper estas imposiciones patriarcales, conviviendo con aparente normalidad con los productos más mainstream.

El presente texto recorrerá algunas series norteamericanas paradigmáticas, mediante una metodología eminentemente teórica y estética con un marco de análisis flexible y relacional que, abierto a las contribuciones de nuevas disciplinas y epistemologías, puede contribuir al enriquecimiento de la investigación audiovisual. Se trata de ofrecer una lectura sobre la presencia y/o ausencia tanto del binarismo de género, y la transgresión (si la hubiera) de los paradigmas identitarios genéricos, así como de las posibles propuestas emancipadoras. Nos interesa analizar hasta qué punto la ficción audiovisual considerada de calidad ha sido capaz de trascender convenciones en relación a los hombres y las mujeres, la sexualidad y la estereotipia. La hipótesis de partida es que las sexualidades y representaciones de género en la ficción se dividen entre una mayoría que consolida el rol patriarcal y unas pocas obras originales con las que la cultura audiovisual intenta horadar el canon audiovisual, proponiendo mensajes emancipatorios.

Los modelos de representación suelen usar estereotipos como repetidas constelaciones de rasgos negativos de los personajes que se convierten en una sólida forma de control social y que, además, implican a unos privilegiados de la representación; por eso, al poner de manifiesto esas relaciones (de raza, clase y género) lo que se pretende es conseguir una igualdad en la representación y un acceso a la propia representación. Puede entenderse que esta es una postura política y no de análisis audiovisual. Desde luego que es una postura política (e, incluso, activista, si se quiere). Pero lo que no se dice nunca es que la postura inversa, de ignorar las cuestiones de género (o raza o clase) es también una postura política.

1 Heterosexualidad normativa: heterosexualidad como única forma (aceptable) de sexualidad. 


\section{Identidad de género y discurso audiovisual}

Los medios de comunicación proponen formas de construir la identidad de género, ya que los individuos son seres sociales: están inmersos en el discurso social, ideológico y económico; de ahí que la forma de entender qué es masculino y qué es femenino responde a cierto canon (de Miguel et al., 2004, p. 10). La televisión crea modelos, y uno de sus recursos es ofrecer situaciones y comportamientos mediante los cuales sugiere escenarios o protagonistas con el fin de que sean interiorizados por la audiencia a través del proceso de inmersión. La ficción es siempre una modelización del universo real, incluso en el caso de los productos más fantásticos. De ahí que la ficción televisiva ofrezca modelos del mundo que luego pueden ser reinterpretados y significados por la audiencia (Schaeffer, 1999, p. 218).

Existe consenso en la bibliografía especializada en cuanto a que las industrias culturales han reproducido el androcentrismo patriarcal, sin cuestionar los estereotipos de género y sin proponer lecturas alternativas que permitan observar los cambios que se están produciendo en la vida de hombres y mujeres. El análisis del protagonismo en la ficción revela un sesgo androcéntrico, al establecer de facto que el varón -y no cualquiera sino más bien el estereotípico- es el sujeto significante. Tanto es así, que ni siquiera la audiencia se incomoda ante la hegemonía de lo masculino en menoscabo de lo femenino. Esta circunstancia se traduce en la existencia de un mundo de ficción donde los varones poseen múltiples y ricas facetas y en el que se consolida un modelo de seducción apoyado en la iniciativa y autonomía masculina frente a unas mujeres dibujadas únicamente como cuerpo para ser mirado. En este sentido, las mujeres siguen siendo el objeto, siempre en posiciones subordinadas o, en el caso de su protagonismo, dibujadas con elementos negativos la mayoría de las veces (Aguilar, 2001, p. 224). Todo ello contribuye al mantenimiento de cierta trivialización de lo femenino y, probablemente, a convertir en audiencias segmentadas los productos que están interpretados por mujeres. Estas características pueden explicar que el protagonismo femenino no sea una apuesta mayoritaria mientras que muchos productos televisivos se articulan en torno a argumentos familiares o profesionales.

En la raíz misma de la preocupación por las cuestiones de género es necesario plantearnos tanto un repensar a la(s) mujer(es) como al(os) hombre(s) ya que si bien la dominación y la explotación (estructural, sistemática e histórica) han sido sufridas por las mujeres por parte de los hombres, no es menos cierto que ellos han sufrido otro tipo de dominación patriarcal que les ha impuesto un concepto cerrado de sí mismos, de masculinidad única (y excluyente), así como de las relaciones entre los géneros, de la sexualidad y del sexo, encerrándoles en una heterosexualidad entendida como la única sexualidad posible -lo "otro" quedaba, por lo tanto, en el lado de la enfermedad, la perversión, el "desvío" y el pecado nefando_- Cuando se habla de representaciones y género se suele asociar inmediatamente la reflexión a la representación de las mujeres, a su posible cosificación, a la sexualización de su cuerpo, belleza o valores. Es mucho menos habitual, máxime en el

2 Según la RAE: 1. adj. Indigno, torpe, de que no se puede hablar sin repugnancia u horror. 
ámbito español, hablar de la representación del(os) hombre(s) y, cuando se hace, se puede apreciar la suma incomodidad que provoca o, simplemente, se remite a una constatación de su rol dominante y protagonista (referida a la mujer) sin entrar en valoraciones sobre su corporalidad, la sexualización de su cuerpo y de su mirada, su belleza, su sexualidad y su deseo. La incomodidad del asunto conlleva el silencio. Y es que la cosmovisión del patriarcado ha sometido a los hombres a un rol de dominio con una interpretación de "lo masculino" normativa, única, exclusiva y excluyente de toda diferencia que provoca, por ello, una interpretación universalista de la "esencia" masculina que, a la vez, es propuesta como el universal y referencia absoluta del ser humano: la mujer viene de la costilla de Adán y, por lo tanto, el hombre es el referente total de la humanidad plena. Ese dominio se vuelve contra el propio ente dominante al no permitirle ser otra cosa que lo estipulado por la dictadura patriarcal; ningún hombre se puede definir por su propia especificidad particular sino, únicamente, por su ser universal "hombre". Pero, una vez puesto en cuestión el estatuto patriarcal no cabe más que poner en cuestión también su pretendida universalidad: ya no cabe hablar de "hombre" o "masculinidad" porque ya no es un concepto único, unívoco, normativo y exclusivo. De ahí que tengamos que hablar de "hombres" y "masculinidades" que no arrastran conceptos unívocos sino plurales, diversas sensibilidades y diferentes maneras de serlo. La ideología patriarcal se puede resistir al cambio, a la revolución (y sustitución) de paradigma, pero ya es inevitable.

\section{Mujeres y feminidad en la ficción}

Para un análisis extenso sobre las mujeres en las pantallas contamos ya con un corpus bibliográfico amplio pero, una síntesis categorial puede concretarse en dimensiones como las siguientes: las mujeres aparecen en inferioridad frente a los hombres, los personajes femeninos acostumbran a representar papeles tradicionales, suelen ser emocionalmente inestables y no pueden competir con los varones (Graydon, 2001). No obstante, algunos productos recientes comienzan a dibujar un cambio, mediante la introducción de trayectorias femeninas que, por una parte, rompen con la tradicional invisibilidad de las mujeres en el discurso mediático y, por otra, permiten subvertir algunos estereotipos de género, por ejemplo en relación con la masculinidad. En este orden de cosas, Amanda Lotz (2006) explica que, a partir de los años noventa, se han comenzado a producir dramas televisivos que ponen el acento en la diversidad de la vida de las mujeres (incluyendo la aparición de heroínas míticas o de ciencia ficción), mediante la utilización de caracteres femeninos positivos y mucho más numerosos que los que presentaba la televisión hasta entonces. Sin embargo, no todos los textos consideran positiva dicha lectura, pues la aparición de nuevas protagonistas, en ocasiones, obedece a perfiles poco o nada interesados en subvertir los roles genéricos, de forma que incluso es posible advertir cierto acatamiento de principios totalmente contrarios a las reclamaciones feministas. Con todo, e independientemente del enfoque más o menos emancipador de cada uno de estos productos, es un hecho que ha habido un cambio, aunque tímido. En él han tenido que ver múltiples factores, entre los que destaca la necesidad de rescatar unas audiencias femeninas poco interesadas por los productos hegemónicos en los que la mayoría de protagonistas tenían como único rol el 
doméstico (madres y amas de casa, sin trabajo remunerado) y su protagonismo se reducía a las comedias. El cambio en la ficción televisiva permitiría que las mujeres aparecieran en narrativas dramáticas, primero asociadas a un varón y con demasiado énfasis en el físico y el atractivo sexual, pero más tarde de forma independiente, con papeles dotados de autonomía, proponiendo historias más complejas y originales.

Sería imposible recoger aquí la cantidad ingente de protagonismo femenino de las dos últimas décadas, por lo que las siguientes líneas intentarán acercarse únicamente de forma exploratoria a algunas cuestiones esenciales. Entre ellas, nos interesa destacar que el patriarcado ha utilizado la rivalidad femenina como argumento socializador, cuestión bien alejada de la realidad de las mujeres pero recurrente en la cultura popular. Así, un cambio significativo respecto a la ficción convencional se produce cuando algunos relatos incorporan un nuevo paradigma, en el que se entiende la amistad femenina como hilo principal, casi como celebración. Quizá la precursora sea la mítica The Golden Girls (NBC, 1985-1992), serie multipremiada que consiguió lo que ninguna otra ficción posterior ha logrado: integrar de forma positiva el binomio mujer y edad. Su discurso sobre las posibilidades vitales que abre la madurez fue sin duda transgresor y plenamente positivo (Menéndez, 2008, p. 80). Fue el primer producto de ficción seriada para televisión íntegramente protagonizado por mujeres, todas ellas maduras. La serie proponía un agudo ejercicio intelectual y mordaz a través de la conversación de cuatro personajes que compartían confidencias, problemas y sobre todo amistad, el factor esencial de su relación.

Claro que antes de su estreno habían existido algunos otros productos con varias mujeres como protagonistas, pero no respondían al perfil transgresor, aunque pudiera parecerlo a simple vista. Es el caso de Charlie's Angels (ABC, 1976-1981) un auténtico éxito en la época, protagonizado por tres detectives expertas en artes marciales, estereotípicas en las cuestiones estéticas y siguiendo un patrón narrativo totalmente patriarcal. El éxito intentó repetirse en fechas recientes pero fracasó. Tal vez porque las espectadoras no estaban ya dispuestas a soportar tanta cantidad de paternalismo y estética erótica convencional. Sin embargo, las aventuras de aquel trío de detectives ofrecía, quizá por primera vez de una forma rotunda, a protagonistas definidas desde un espacio profesional, algo que muchas series de los años noventa iban a explotar como un auténtico filón.

Es emblemática Ally McBeal (Fox, 1997-2002), donde una mujer, por primera vez, protagoniza en solitario una serie "profesional". Las herramientas originales que ofrecía esta ficción fueron, sobre todo, la naturalidad de la abogada que da nombre al producto y la frescura de unos guiones que también incluían información sobre la práctica de la abogacía (abordando temas como el acoso sexual, por ejemplo). La serie tuvo una audiencia, en Estados Unidos, mayoritariamente femenina (61 \%), un tercio de ellas, jóvenes. Aparecía un nuevo perfil: el de la profesional que busca la realización personal mediante su carrera, aunque buscaba desesperadamente una pareja. Ally McBeal rompió con la monotonía de las series ambientadas en el mundo del derecho, con una apuesta novedosa: una protagonista joven, de sexo femenino y con una personalidad arrolladora, integrada 
a partes iguales por ingenuidad, talento, osadía y humor. Además, los códigos formales de ambientación y narrativos serían subvertidos y la producción se convirtió en una obra de culto que dio lugar a un spin off. Tras ella, las obras ambientadas en juzgados o bufetes han sido muy numerosas pero quizá hay que destacar, un producto reciente, firmado por el mismo creador que Ally McBeal o Boston Legal (David E. Kelley): Harry's Law (NBC, 2011 2012) con Kathy Bates por primera vez en televisión como protagonista. En esta ficción, Bates es la abogada Harriet Korn, un personaje excéntrico, fuerte e interesante, que tiene que reconducir su profesión de abogada de patentes a defensora de las personas más desfavorecidas. El creador ha reconocido que escribió el papel para un varón pero, al no encontrar un actor adecuado, lo reescribió para una mujer. La estela de McBeal también ha sido seguida por otro drama reciente: Fairly Legal (USA Network, 2011-2012) cuya protagonista no tiene prácticamente nada en común con la anterior. El atractivo de la actriz (muy popular tras encarnar a una de las protagonistas de The L-World) no fue suficiente para sostener una historia aburrida y nada original según la audiencia. Su corta duración, como la protagonizada por Bates, revela lo difícil que es repetir el éxito de McBeal. Si bien son muy numerosas las series que se desarrollan en el campo del derecho, no lo son tanto las que tienen un protagonismo incontestable femenino. Mención aparte merece The Good Wife (CBS, 2009-Actualidad), con un gran elenco femenino y un argumento que nos ofrece una (clásica) esposa engañada por un marido infiel que debe volver a su empleo como abogada tras el encarcelamiento de aquel por corrupto.

A caballo entre las series legales y las médicas se encuentran las de investigadoras, detectives y forenses, donde muchas protagonistas han llevado adelante con éxito papeles protagónicos que se apoyan en un perfil de mujer muy inteligente y con gran formación. Es el caso de Bones (Fox, 2005-Actualidad) con su brillante arqueóloga forense Temperance Brennan; Castle (ABC, 2009-Actualidad) y su detective Kate Beckett, o la reciente Rizzoli \& Isles (Turner Network Tv, 2010-Actualidad) protagonizada por una detective, Angie Harmon, y una patóloga forense, Maura Isles. La ficción televisiva se basa en una serie de novelas de Tess Gerritsen que tiene como protagonista a Isles. Rizzoli e Isles, amigas y compañeras de trabajo, son dos mujeres amantes del riesgo y adictas al trabajo.

Pero, sin duda, en las series profesionales destacan las médicas. Aparte de aquellas que ofrecen estupendos perfiles femeninos aunque no protagonistas -muy numerosas pues en estas narrativas es frecuente el protagonismo coral-, existen varias que pueden elegirse como exponentes de nuevos roles en la ficción. A destacar la interesantísima Strong Medicine (Lifetime, 2000-2006) producida por Whoopi Goldberg -que incluso hizo algún cameo-, y con el foco narrativo en el feminismo, la salud femenina y los problemas de exclusión social. Una serie que, sin embargo, ha pasado bastante desapercibida, quizá por tener un enfoque tan claro sobre los problemas de las mujeres y un elenco enteramente femenino. No le sucedió lo mismo con la exitosa Grey's Anatomy (ABC, 2005-Actualidad), serie que desde el punto de vista de género ofrece pocas cuestiones interesantes. Si bien la primera temporada había definido perfiles femeninos profesionales y competitivos, más tarde derivó en un drama romántico mucho más convencional. Quizá eso explica su éxito. 
Lo que no puede negarse a Ally McBeal es que abrió un camino que sería explotado en muchas obras posteriores, muchas de ellas citadas en los párrafos anteriores. Se trata de dibujar un personaje que a duras penas encuentra el equilibrio entre la brillantez y precisión de su vida profesional y la dispersión, inmadurez y desequilibrio en la privada, características estas relacionadas con la socialización femenina. Así por ejemplo podemos observar la relación con la comida: el miedo a la ingesta en general como sucedía en The Golden Girls, a la bollería industrial como ocurre en The Closer (TNT, 2005-2012), la adicción al chocolate o el miedo al compromiso: las protagonistas buscan el príncipe azul pero luego no se comprometen, es el caso de Grey's Anatomy en sus primeros capítulos, de algunos personajes de Sex and the City y, desde luego, de Ally McBeal. Constituye una reproducción de los estereotipos de género porque define a las mujeres como emocionales y temperamentales, haciendo hincapié en la emotividad y vulnerabilidad como características más sobresalientes, algo que no por frecuente es menos paradójico: permite la identificación de la audiencia femenina (pues las mujeres han sido socializadas en el paradigma patriarcal) pero consolidan el sexismo en lugar de superar los estereotipos.

Retomando la idea de la solidaridad y empatía entre mujeres como elemento de subversión, es necesario mencionar Gilmore Girls (Warner Bros, 2000-2007) donde aparecen varias relaciones interesantes: la de las dos protagonistas -madre e hija, Lorelai y Rory-, la de las amigas -Lorelai y Sookie- pero también la difícil relación entre Lorelai y su propia madre, Emily. Con esta ficción termina el arquetipo de la madre/ángel del hogar y se normaliza la posibilidad de una maternidad en solitario. Al mismo tiempo, se presenta de forma bastante realista una relación beligerante entre Lorelai y Emily, cuya forma de entender la vida es muy distinta, fulminando así la idea utópica de la familia como lugar sin conflictos. En este caso, la ficción ha privilegiado una relación de complicidad y, sobre todo, la autonomía (el contestador de Lorelai es expresivo al respecto: "No estamos. Tenemos una vida. iQué le vamos a hacer!"). Tremendamente culta e inteligente, los guiones de esta serie estaban plagados de alusiones al feminismo, el cine, la música rock y pop, la política o la literatura.

No obstante, hablar de autonomía y amistad entre mujeres remite inevitablemente a Sex and the City (HBO, 1998-2004), probablemente la más mítica de todas las series protagonizadas por mujeres en los noventa y también la más criticada; defendida y denostada a partes iguales por quienes la consideran feminista y quienes opinan todo lo contrario. Los guiones de esta obra no se interesaron, como había sido frecuente hasta entonces, por cuestiones domésticas o familiares, sino que pusieron el foco en las relaciones sociales y el ocio. Según Blum, Sex and the City ofreció a sus protagonistas lo que su creador-Darren Star- no había podido hacer con los personajes de sus obras anteriores: la libertad. De ahí que sean mujeres que eligen "el placer y el poder" (Blum, 2011, p. 117). Y, en esa ecuación, un vector principal será la amistad. Más allá de los problemas que la serie presentaba desde el punto de vista de género, es interesante rescatar la lectura feminista que proveía (Menéndez, 2013, pp. 221-227): protagonistas con independencia económica e iniciativa y autonomía sexual; construcción de un punto de vista femenino que permitía pensar y relatar la sexualidad de forma inédita; abordaje de problemas existenciales relacionados 
con el género; voz propia para las mujeres; y, especialmente, celebración de la solidaridad femenina como hilo conductor. Fue la primera serie de televisión que se atrevió a ofrecer espacio para que las mujeres hablaran entre sí de sus problemas e intereses, sin cuestionar si eso iba a gustar o no a los varones, de una forma que probablemente no se ha vuelto a repetir en la televisión.

Muchas personas han querido ver en Desperate Housewives (ABC, 2004-2012) una continuación de Sex and the City, pero lo cierto es que ambas series tienen poco que ver. Lo que sí ofrecen es un discurso, como la serie anterior, atravesado por la ambigüedad pues, de acuerdo con Marcucci, Desperate Housewives es una serie al tiempo conservadora y al tiempo progresista, en la que se pueden encontrar tanto el feminismo como la misoginia (Marcucci, 2012). Esta ficción tiene la virtud de ofrecer la tensión que sienten muchas mujeres contemporáneas: entre lo que quieren y lo que la sociedad espera de ellas, pues señala la escisión entre la educación recibida - ser una buena madre y ama de casa- y el deseo de ser alguien en la sociedad. Si hasta el cambio de siglo la televisión había presentado un perfil profesional muy rotundo (Ally MacBeal, Murphy Brown) eso tuvo otra consecuencia: la pérdida de referentes en el mundo privado. De ahí que podamos observar en el personaje de Lynette Scavo el sentimiento de culpabilidad de las mujeres con empleo, mientras Bree van de Kamp llega casi a la locura en su obsesión por construir una familia perfecta.

Girls (HBO, 2012-Actualidad) es quizá la más reciente de las propuestas transgresoras con un protagonismo íntegramente femenino. Considerada con frecuencia como una secuela de Sex and the City (cuatro mujeres jóvenes en la misma ciudad y con referencias explícitas al sexo), desde el punto de vista estético es la antítesis de aquella, podría decirse que se trata de su versión hipster. Su narrativa poco convencional y su público objetivo -mujeres más jóvenes- pueden explicar el éxito que tiene una obra que deja atrás cualquier idea patriarcal sobre lo femenino.

No debemos olvidar, por último, el papel de la hetenormativa en la ficción, una constante tímidamente transgredida en algunos personajes de series contemporáneas (las doctoras Kerry Weaver y Kim Legaspi en ER/Urgencias; Callie y Arizona en Anatomía de Grey; Kim Daniels en Sugar Rush; Ashley Davies en South of Nowhere; Nikki y Ellen en Bad Girls) que demuestra que, aunque puede haber lesbianas en tramas secundarias, es más difícil que ocupen la narrativa principal, tal y como ocurre en The L-World (Showtime, 20042009). No obstante, suele considerarse Ellen (ABC, 1994-1998) como la primera serie con una protagonista lesbiana, interpretada por Ellen Degerenes, pero cuya homosexualidad no aparece hasta la cuarta temporada, en el famoso episodio "The Puppy Episode", uno de los más vistos en la historia de la televisión norteamericana.

Lo expuesto en las líneas anteriores permite asegurar que el protagonismo femenino en series comerciales para televisión es en sí mismo una forma de transgresión porque, además de paliar una invisibilización habitual en las industrias culturales, muchas de esas ficciones han logrado romper estereotipos de género. Son series que a veces se atreven a abordar temas tabú (como la iniciativa sexual, la diversidad sexual o el abandono del 
rol maternal), pero también se trata de discursos que se interesan por los asuntos de la esfera femenina, casi siempre invisibles. Con todo, se puede hablar de la perversidad de un modelo supuestamente emancipador, pues muchas protagonistas siguen buscando un príncipe azul como elemento central, aun cuando son personajes definidos esencialmente desde su empleo. Es decir, la mayoría de ficciones sitúan a las mujeres en un discurso que las define como "incompletas" si no encuentran pareja, independientemente de cuestiones objetivamente emancipadoras. Con todo, muchos de estos personajes ofrecen un perfil fuerte, independiente y muy inteligente, sin caer -al menos no siempre- en perfiles histéricos o negativos.

\section{Representaciones televisivas de (nuevas) masculinidades}

Los valores adjudicados a la masculinidad por el patriarcado (sexismo falocrático, heterocentrismo, individualismo, competitividad, activismo dominante, hegemonía, dominio de la esfera pública, minusvaloración de la esfera privada -propia de las mujeres-, permanente obsesión por el éxito, el trabajo, el ejercicio de la fuerza, la fortaleza y la represión de los niveles básicos emocionales y de las actitudes afectivo-relacionales) están en crisis. El macho se definía y representaba como el auténtico ser humano; él no es mujer (es decir, un ser débil, dubitativo, emocional, pasivo y dependiente) ni maricón (que no es sino la corrupción de la virilidad, un hombre que se corrompe al feminizarse y, por lo tanto, que ya no merece ser considerado masculino o una mujer que osaba salirse de su esfera para igualarse al hombre). El macho era ajeno a "lo diferente", formaba un todo común con los otros machos. Las diferencias raciales eran percibidas como diferencias básicas en el desarrollo donde, por supuesto, el hombre occidental (blanco) representaba el culmen de dicho desarrollo de masculinidad. Las diferencias de clase eran percibidas también como manifestación de éxito pero no disminuían ni cambiaban el sentido de "macho" de esos hombres. Es por ello que "la masculinidad hegemónica se fundamenta y autoafirma a través del sexismo, el racismo y la homofobia" (Carabí, 1996, p. 28).3

Ante ese panorama lo que se plantea es un repensar en los valores plurales que puedan definir a los "nuevos" hombres. Se trata de una auténtica deconstrucción (de los viejos valores patriarcales) y una nueva reconstrucción de Adán (con los nuevos valores de la masculinidad liberada). Siguiendo el conocido argumento de Teresa de Lauretis, el género es representación y la representación del género es su construcción. Es decir, el género se construye en la representación de las ideas imperantes que señalan cómo debe actuar dicho género. De ahí la máxima importancia de intervenir en la representación, porque esa intervención libera el esquema normativo.

Y, en el sentido que nos ocupa, la cuestión es ¿cómo ha evolucionado la representación de las masculinidades en la televisión? Es una pregunta que, obviamente, excede las dimensiones de esta propuesta, aun acotando a la televisión norteamericana. Desde siempre han existido personajes masculinos que, aun estando plenamente situados en el eje patriarcal introducían ciertos matices, la mayor parte de las veces, por ser excesivamente "bonachones"

3 Véase González (1996) para un cruce entre masculinidad y raza. 
y "tolerantes" con las "singularidades" de sus fuertes mujeres (aunque siempre terminaban por sobreponerse y situarlas en su sitio en la casa). Es el caso, por citar un ejemplo, de Darrin Sthephen en Bewitched (ABC, 1964-1972), lidiando con su duro trabajo de publicitario y con una mujer bruja (Samantha) a la que le prohíbe ejercer como tal pero que siempre se mete en algún embrollo muchas veces por la intervención de su madre Endora, la suegra enredadora de Darrin. Habitualmente este tipo de personaje encajaba más en comedias ligeras familiares que en dramas o series policiacas donde la masculinidad se representaba sin fisuras, como garantes, bien por policías, bien por abogados, del orden establecido.

La ficción televisiva, podríamos decir, se ha desarrollado según los cánones establecidos de la representación por el orden patriarcal, aunque no ha sido ajena a los cambios sociales que se han ido produciendo. Así, por ejemplo, han irrumpido personajes protagonistas afroamericanos; el primero más célebre sin duda fue The Cosby Show (NBC, 1984-1992). Y, obviamente, poco a poco, han introducido personajes masculinos que se "desviaban" en ciertos "aspectos" tradicionalmente considerados masculinos (aunque siempre respetando la norma heterocentrista). La NBC ha sido una de las cadenas pioneras en la introducción de estos nuevos arquetipos de representación. Sitcoms como Fraiser (NBC, 1993-2004); Friends (NBC, 1994-2004); Seinfeld (NBC, 1989-1998, años más tarde será también significativo el caso de la serie de uno de sus creadores, Larry David y su serie Curb Your Enthusiasm); Mad about You (NBC, 1992-1999); Northern Exposure (CBS, 19901995) o Will \& Grace (NBC, 1998-2005) replantearon incuestionablemente la masculinidad dominante y heteronormativa.

El caso de Fraiser (NBC, 1993-2004; recordemos que se trata de un spin off de la serie Cheers) es emblemático y muy avanzado. El hilo conductor de la serie es la representación de unas masculinidades diferentes, en clave de humor, pero que, episodio a episodio, cuestiona la norma masculina dominante. Frasier Crame es un psiquiatra que representa un hombre refinado, intelectual, de gustos exquisitos, un tanto snob, siempre bien vestido, con un apartamento de soltero de estudiado interiorismo (se enorgullece de su sofá copia del que tenía en su estudio Coco Chanel) y de modales tan delicados que le presentan como un heterosexual (sin dudas sobre su gusto por las mujeres) que parece siempre gay, un heterogay, tal vez el primero de la ficción televisiva, que solamente es ganado en refinamiento por su propio hermano Niles (David Hyde Pierce) y, por contraste, su padre (Martin, John Mahoney), un policía retirado que representa la clásica masculinidad que no sabe cómo encajar ni manejar a un(os) hijo(s) tan intensamente "sofisticado(s)". En la actualidad series como Entourage (HBO, 2004-2011) o Nip/Tuck (FX, 2003-2010) juegan con el concepto de una masculinidad diversa, que muestra a unos hombres muchas veces perdidos en sí mismos, a quienes cuesta entender la evolución de la sociedad pero que desean ser triunfadores y vivir su propia vida, tomando sus propias decisiones sin seguir la estructura impuesta por el patriarcado, que pueden arrepentirse de lo acontecido en el pasado y cambiarlo.

Otra serie que indaga en la misma idea es la canadiense, también de audiencia en Estados Unidos, Naked Josh (Showcase, 2004-2006), de Alex Epstein y Laura Kosterski, donde se presentan dos modelos antagónicos de masculinidad: por un lado, el protagonista, Josh, 
un profesor de antropología sexual en la Universidad de Montreal, representante de ese nuevo hombre sensible que no busca relaciones esporádicas, sino un proyecto estable de pareja con una mujer y su propio proyecto de vida; por el otro, su amigo, el típico hombre mujeriego un tanto descerebrado pero que se da cuenta de que las mujeres son las que muchas veces le usan a él y no al revés, que tantas veces le gusta creer. La serie trata, en general, el complicado mundo de las relaciones personales y el sexo. No deja de ser significativo que una mujer sea co-creadora de la serie.

Big Shots (ABC, 2007-2008), por otra parte, es - pretendidamente- un Sex and the City pero a la masculina; a través de sus reuniones, los amigos podrán poner en común sus problemas con las mujeres o con su vida en general y tratar de darles una solución (nunca se vio en una ficción audiovisual, televisiva o no, hablar tanto a cuatro hombres). Con ella se trata de mostrar la pretendida problemática del hombre actual, que sigue un modelo de masculinidad que muchas veces le cuesta comprender la evolución de las relaciones de género y donde ellos no siempre detentan el poder (ni económico ni social ni sexual). O, más recientemente, Big Bang Theory (CBS, 2007-Actualidad), donde podemos ver diferentes formas de masculinidad también marcadas por cuestiones de cultura y raza. Los jóvenes físicos y profesores (del California Institute of Technology o «Caltech») protagonistas de la serie, son unos perfectos geeks, claro ejemplo del novedoso triunfo freak en la ficción audiovisual: patosos, fuera de la realidad, listos y de los cuatro protagonistas, uno es judío-americano y otro indio, enamorados de sus cómics, del cine de serie B, la ciencia ficción y en constante lucha por conseguir novia (salvo que Sheldon Cooper, Jim Parsons, que, simplemente, se la "encuentra" sin más).

También plantea cuestiones parecidas sobre la masculinidad la serie Chuck (NBC, 2007-2012). Un joven enclenque e inteligente chico patoso (Chuck Bartowski, Zachary Levi) que por intervención informática se convierte en un súper espía que, no obstante, necesita constantemente ser salvado por la atractiva, inteligente, fuerte, empoderada y determinada agente de la CIA, Sarah Walker (Yvonne Strahovski), de la que termina perdida y románticamente enamorado, en una clara transferencia de roles (según los esquemas clásicos de representación de género): él soñador, ensimismado, hablador, romántico y sentimental y ella racional, fría, calculadora y distante.

Desde otra dimensión histórica Mad Men (AMC, 2007-Actualidad), ambientada en los años sesenta (al menos por ahora), sin embargo, plantea (por contraste) las ideas mismas sobre masculinidad haciendo que, al visualizarla con los ojos de hoy, pensemos más si cabe en su transformación y cómo ha dejado de ser la norma hegemónica ese tipo de hombre macho hetero y prácticamente misógino. Otros destacados casos son Dexter (Showtime, 2006-2013); House (Fox, 2004-2012) o Scrubs (NBC, 2001-2008 y ABC, 2008-2010).

Quisiéramos destacar el fenómeno televisivo que está siendo la serie de Alan Ball, ${ }^{4}$ True Blood (HBO, 2008-Actualidad), un ejemplo de cómo desde una realidad fantástica situada

4 Creador de una serie emblemática que suele ser citada como el inicio de una nueva televisión, Six Feet Under (HBO, 2001-2005) importante también para el estudio de las representaciones de las masculinidades, con un abanico variado de hombres, con diferentes orientaciones sexuales y diferentes modos de encarnar su propia masculinidad. 
en un futuro cercano en el que los vampiros y otros seres (mutantes, hombres lobo, brujas y brujos, hadas y hados, etc.) conviven (más o menos bien) con los humanos. Gracias a esa gran variedad de seres se nos proponen también un sinfín de cuestiones sobre género y, concretamente, sobre los valores y articulaciones de sus respectivas masculinidades nunca definidas por su orientación sexual (una gran novedad a la hora de definirla) y que incorporan, además, una estética erótica permanente y buscada. La presencia de la sexualidad es continua, y tanto mujeres como hombres constantemente muestran sus deseos, sus cuerpos, su actividad sexual y sus inclinaciones. Con total naturalidad se muestran personajes heterosexuales, homosexuales y bisexuales, hombres y mujeres, que muestran cómo dicha orientación sexual no supone ningún tipo de menoscabo a su identidad como hombre o como mujer. Resulta significativa y novedosa esta forma de representar las masculinidades que no son un cuestionamiento a la masculinidad per se, sino un cuestionamiento a la ideología patriarcal sobre la masculinidad y sus (apriorísticas) imposiciones ideológicas. No se pretende cuestionar ni la propia masculinidad ni la de los demás. Aquí permanentemente se ven los cuerpos desnudos de vampiros, vampiresas, hombres y mujeres lobo, mutantes, brujas y brujos, hadas y hados y, por supuesto, también los humanos; se les ve tener sexo con mujeres o con hombres (o con ambos) y se consigue que el espectador masculino siga la serie sin entrar (al menos del todo) en esa incomodidad defensiva que tantas veces le puede producir la visualización de la desnudez corporal de otros hombres (por sentir vulnerable, de ese modo, su masculinidad). El éxito puede deberse a ese ambiente "mágico" que plantea una neo-realidad pero también es cierto que se consigue una normalización en el visionado haciendo girar el objeto del (placer) visionado (Mulvey, 1988).

Men at Work (TBS, 2012-Actualidad) es, seguramente uno de los más preclaros ejemplos actuales. Una sitcom que se nos presenta con unos títulos de créditos con fotografías, de principios del siglo XX, de hombres trabajando (mayoritariamente) en trabajos físicos, hombres prematuramente mayores, serios, abrumados, duros, sudorosos, sucios, velludos, descuidados y de contundente presencia física no estetizada, que contrasta con los cuatro protagonistas: hombres heteros de físicos cuidados, fibrados pero no musculados, se nota que la mayoría de ellos hacen habitualmente ejercicio físico (tal vez menos Adam Busch, interpretado por Neal Bradford que, curiosamente es el único con novia en la serie) pero como placer y/o opción saludable y estética, no por obligación (como los hombres de los títulos de crédito) y con profesiones nada "físicas": editores, escritores y fotógrafo de una (norteamericana) revista masculina. Milo (Danny Masterson) es abandonado por su novia y nos ofrece un cambio de roles en la habitual representación de este tipo de secuencia: él intentando (suplicándole) que ella no lo deje, ella diciéndole que no es por él sino por ella... Sus tres amigos y compañeros de trabajo le ayudarán a "volver al mercado" de solteros al que pertenecen dos de ellos (el blanco rubio y guapo, Tyler -Michael Cassidy-, y el afroamericano ligón, Gibbs -James Lesure-) puesto que el único que tiene pareja es, en definitiva, el hombre que, a priori, según el esquema tradicional, es el menos masculino, el menos guapo, el menos cool, el más débil, el más raro... Por ejemplo, en el capítulo 4, "Heterotextual" (en la versión doblada al español lo definen como "Machotex- 
tual"), sus amigos le explican a Milo cómo ser un hombre interesante para las mujeres del 2012 después de los años que ha estado con novia y, por ello, desconectado de la nueva realidad de las mujeres.

Todos estos ejemplos nos hacen ver cómo las ficciones televisivas siguen siendo uno de los pilares básicos de la construcción del imaginario social y, por eso mismo, una de las principales herramientas en el cambio de mentalidad que se está operando en la construcción de las nuevas masculinidades. No en vano es un trabajo arduo que necesita referentes, ya que consiste en desmontar toda la mitificación de la masculinidad y la heterosexualidad normativa operada por el patriarcado y acomodarla a una realidad donde la mujer es un sujeto activo tanto en lo personal, como en lo social, lo profesional, lo económico, lo político y lo sexual.

En general podemos ofrecer una catalogación de características a la hora de la construcción de los personajes masculinos y de su arco de personaje, con la premisa mayor (siempre) de no ser personajes que ofrezcan una masculinidad universal ni un modelo de representación como metáfora de un hombre que engloba todo el sentido de la masculinidad e, incluso, de la humanidad misma (Zurian, 2011). Toda construcción de personajes juega con la simplificación de la realidad en la generalización de una imagen consensuada por un grupo de personas o grupos, sobre otras personas u otros grupos, que se transfieren en el tiempo. Con todo, en la construcción de relatos, en la creación de ficción y, en general, en el artificio de la representación, el uso de los arquetipos es ocurrente y necesario en orden, por un lado, a la construcción de caracteres (personajes) y, por otro, a facilitar la identificación por parte del público (consumidores). De este modo los arquetipos juegan con modelos de caracterización que permiten esa doble necesidad por medio de la descripción física, psicológica y del entorno social. En el caso de los personajes masculinos se suele desarrollar, en cuanto al físico, una obsesión por la fuerza, la dureza y los músculos, incluso por la búsqueda de una belleza masculina (especialmente en la actualidad): el cuerpo como muestra de vigor y virilidad; la corporalidad como manifestación de su poder y su capacidad de triunfo; ahora también como arma de seducción (anteriormente solamente se contemplaba ésta posibilidad en las mujeres) y poder sexual (se fomenta la mirada de la mujer hacia la corporalidad masculina pero también la mirada homoerótica y no solamente buscando la complicidad con el posible público gay). Pero ahora, a diferencia de otros tiempos, el cuerpo ya no tiene que ser necesariamente velludo; se visibiliza también el cuidado corporal por medio de cuerpos depilados (o con el vello "justo", delineado y nunca donde no debe estar), forjados en el gimnasio y nada ajenos ni a la moda ni a su conciencia de poder sexual. Si antes el modelo era un Tarzán salvaje, ahora es un hombre mucho más sofisticado, aunque duro, cuidado y moldeado, buscando definición cuando no un gran volumen de músculos, marcando un pecho grande y fuerte, visibilizando los abdominales de forma escultórica y piernas recias, dejando insinuar un buen tamaño en su miembro viril.

En cuanto a su psicología, tradicionalmente los hombres se solían mostrar racionales y poco sentimentales, individualistas (aun estando en grupo) y ambiciosos (acompañado 
todo ello de una cierta arrogancia y suficiencia), muy competitivos, sin miedo, con arrojo y valentía (muchas veces temerarios); eran líderes natos, agresivos para defender su territorio y su posición de dominio; si le es útil mentirá y manipulará, es peligroso y no tolerará la infidelidad ni la traición; pero actualmente se han vuelto mucho más complejos. Se reconocen más vulnerables, menos seguros de sí mismos o, mejor, con una seguridad menos soberbia pero con "actitud", más comprometidos, su trato con las mujeres y su nivel de compromiso de pareja son más respetuosos y más igualitarios. En cuanto a su entorno social tradicionalmente el hombre ocupa por definición la esfera de lo público (trabajo, política, deporte, diversión, bares) y el poder; se remarca su profesionalidad y su sociabilidad; es el cabeza de la familia (ahora menos); se siente (y es) libre, autónomo, con capacidad de decisión y de elección, participa en equipo (en el deporte, en la ganadería amistosa, los negocios, etc.). Actualmente se le presenta también en la esfera privada (tradicionalmente lugar de los personajes femeninos): el hogar, la familia y la intimidad con su pareja y/o amigos ya son un lugar común para los personajes masculinos. También lo podemos ver vulnerable, dependiente (incluso de una mujer) y desorientado. El hombre puede abarcar ya cualquier ámbito de representación social. Y esa es una muestra de la transformación de su arco de personaje y una muestra preclara del cambio acaecido.

Usualmente se establecían ciertos modelos de caracterización típicos como eran el macho, el donjuán, el guerrero, el héroe, el indomable y el villano. Los estereotipos de los hombres en la ficción audiovisual tienden a ser atractivos, con personalidad y activos, mientras que las mujeres quedan relegadas al grado de jarrón, detrás, sin apenas ningún tipo de actividad interesante que se aleje de la mera contemplación de su belleza o de su bondad y virtudes como mujer según la visión del patriarcado5. Actualmente podemos hablar también del inadaptado, el antihéroe, el eterno adolescente inmaduro (síndrome de Peter Pan), el profesional, el padre, el hijo, el amigo. Se pueden establecer dicotomías que vienen marcadas por la diferente caracterización de los personajes masculinos; así podemos tener, hombres de apariencia vulgar frente a hombres guapos; perdedores, frickies, geeks, nerds frente a triunfadores, dominantes, machos alfa; inmaduros, eternos adolescentes o posadolescentes, frente a hombres maduros, con objetivos y un proyecto vital; hombres normales (ordinarios) frente a héroes $y$, por supuesto, hombres heterosexuales frente (pero no necesariamente enfrentados, como sucedía antes) a hombres homosexuales, aunque lo que más destaca en este cambio de las políticas de representación no es tanto el rol sino, más bien, la forma nueva de encarnar dichos roles. Por eso se trata, como decíamos, de "des-universalizar" lo masculino (patriarcal) de la misma manera que otros factores que determinan la identidad están particularizados. Basta con contemplar a cada hombre en su singularidad, como encarnación diferente y plural de los diferentes modelos masculinos propios de las culturas y sociedades donde se ubican, abandonando para siempre el vocabulario y la representación que pongan en el mismo plano lo masculino y lo humano.

5 Véase: Claire Johnston en "Women's Cinema as Counter Cinema". Ensayo escrito por primera vez para el Women's Event del Festival de Cine de Edimburgo de 1976. 


\section{Consideraciones finales}

La ficción televisiva contemporánea, si bien no ha roto con los estereotipos de género ni se ha convertido en un vehículo de emancipación femenina o cuestionamiento de la masculinidad canónica patriarcal, sí estaría permitiendo la irrupción de nuevos discursos ficcionales que comienzan a socavar las bases androcéntricas y heteronormativas de los discursos mediáticos. Las negativas críticas que, en ocasiones, reciben las series protagonizadas por mujeres o por personajes masculinos que no responden al arquetipo viril dominante quizá explican la incomodidad que todavía siente la sociedad ante quienes deciden no plegarse a los designios normativos patriarcales. La desvalorización de "lo otro" puede observarse en que, generalmente, las series que hemos recogido en los epígrafes precedentes, muchas de ellas con gran calidad técnica y creativa, riesgo narrativo y apuestas novedosas en lo estético y discursivo, no suelen incluirse en los listados sobre las mejores series de televisión, tan de moda entre crítica e investigadores/as. Sin embargo, y aunque no disfruten del estatus que muchas de ellas merecen, desde un punto de vista de género ofrecen retos imprescindibles para la reflexión contemporánea puesto que permiten proponer otros modos de representar el género y la sexualidad, amplían el espectro representacional y ofrecen distintos (y variados) modelos de representación que, sin duda influyen en el público y en la visión social general. El audiovisual como vínculo de expresión de la realidad social y de los cambios que se operan en su seno, así como motor de dicho cambio tiene en los productos ficcionales televisivos una de sus principales herramientas y armas de transformación.

\section{Referencias bibliográficas}

Aguilar, P. (2001). Mujeres de cine: retratos mágicos pero distorsionados. En B. Muñoz (coord.), Medios de comunicación, mujeres y cambio cultural (pp. 221 244). Madrid: Dirección General de la Mujer de la Comunidad de Madrid.

Blum, C. (2011). Séries. Une addiction planétaire. París: Éditions de la Martinière.

Carabí, À. (2006). Construyendo nuevas masculinidades: la representación de la masculinidad en la literatura y el cine de los Estados Unidos (1980-2003). Madrid: Instituto de la Mujer.

De Miguel, C. et al. (2004). La identidad de género en la imagen televisiva. Madrid: Instituto de la Mujer.

González, R. (ed.) (1996). Muy Macho. Latino Men Confront their Manhood. Nueva York, Londres, Toronto, Sidney y Auckland: Anchor Books \& Doubleday.

Graydon S. (2001). The portrayal of Women in Media: the good, the bad and the beautiful. En B.D. Singer (ed.), Communications in Canadian Society (pp. 143-171). Scarborough: Nelson Canada Ltd.

Lotz, A. (2006). Series de televisión redefinen los roles de mujer. En University of Michigan. Disponible en: http://espanol.umich.edu/noticias/comunicados-de-prensa/2006/07/24/series-de-televisinredefinen-los-roles-de-la-mujer/

Marcucci, V. (2012). Desperate Housewives. Un plaisir coupable? París: PUF.

Menéndez, M. I. (2008). Discursos de ficción y construcción de la identidad de género en televisión. Palma de Mallorca: UIB. 
Menéndez, M. I. (2013). ¿Cayó el feminismo con las Torres Gemelas? Sexo en Nueva York antes y después del 11 -S. En M. Fernández (ed.), La década del miedo. Dramaturgias audiovisuales post-11 de septiembre (pp. 209-239). Berna: Peter Lang.

Mulvey, L. (1988). Placer visual y cine narrativo. En Eutopías, 2a época (Documentos de trabajo del Centro de Semiótica y Teoría del Espectáculo, Departamento de Teoría de los Lenguajes, Universidad de Valencia). Valencia: Ediciones Episteme.

Schaeffer, J. M. (1999). Pourquoi la fiction? París: Seuil.

Zurian, F. (2011). Héroes, machos o, simplemente, hombres: una mirada a la representación audiovisual de las (nuevas) masculinidades. Secuencias. Revista de Historia del Cine, 34, pp. 32-53. 
